\title{
Tourism Event Management System Using Gianyar Smart Tourism Based On Cloud
}

\author{
I Putu Agus Eka Pratama ${ }^{1}$, and Kadek Ayu Wirdiani ${ }^{2}$ \\ ${ }^{1}$ Information Technology Departement, Faculty of Engineering \\ Udayana University (UNUD) \\ Jimbaran, Badung, Bali, Indonesia \\ eka.pratama@unud.ac.id \\ ${ }^{2}$ Information Technology Departement, Faculty of Engineering \\ Udayana University (UNUD) \\ Jimbaran, Badung, Bali, Indonesia \\ ayu_wirdi@yahoo.com
}

\begin{abstract}
Tourism event data data in Gianyar regency must be managed well, so that it can giving knowledge to all event organizers about tourist interest of all tourism objects around Gianyar Regency. The knowledge also helping them for strategy determination and decision making. Each event organizer can manage their own tourism event data into the system and all of data can be processed to be information and report for the tourist, to make tourism service in Gianyar Regency better. This paper show the design, implementation, and testing of Tourism Event Management System using Gianyar Smart Tourism based on Cloud for all event organizers in Gianyar Regency, developed using Design Science Research Methodology (DSRM) and tested using User Accepted Testing (UAT). It also act as Knowledge Management about tourism event data and tourist demand. Conclusion, all tourism event can be managed well and all event organizers can manage their tourism event data easier.
\end{abstract}

Index Terms - Design Science Research Methodology, Gianyar Smart Tourism, Tourism Event Data Management, User Accepted Testing (UAT)

\section{INTRODUCTION}

Gianyar Regency famous with its tourism in field of art, culture, nature, and history. In case of tourism, there are a big scale of tourism data (one of them is tourism event data), that came from many sources (i.e. : information system, application, user) and stored in many separated servers. This condition make event organizer difficult to using and analyzing data. They also difficult to get the knowledge from tourism data. It's need an integrated information system based on Cloud to collect and manage tourism event data, and also as a Knowledge Management for all event organizers.

Knowledge Management is a system to manage asset and knowledge data at organization, combined with the strategy, process, system, and technique, to gain the goal of organization [2]. The use of Knowledge Management in tourism field has been done by some researchers in their publications, i.e. : Tourism Knowledge Management using Tourism Value Chain and Learning Experience Client [6], Knowledge Management as a hub for tourism service and health service[4], and also Knowledge Management for tourism at Austria [1]. This paper explain the goal of research using Tourism Event Management Information System based on Cloud as Knowledge Management in the case study of Gianyar tourism, to provide knowledge and education for all event organizers around Gianyar Regency, so that it can increase tourism event service to all tourist and realize one of Gianyar Smart Tourism project goals.

\section{METHODS}

\section{A. Design Science Research Methodology (DSRM)}

Research methodology that used in this research is Design Science Research Methodology (DSRM), thats consist of eight steps, including : study literature, problem 
identification, research goal determination, design and development of solution, demo, testing, discussion, and conclusion [5]. The method for collect the data is using survey and interview. Survey took some places of event organizer around Gianyar Regency and interview to them, so that their problem can be determined. It's also to know how far they understand about tourism event data management and its benefit.

\section{B. User Accepted Testing (UAT)}

Testing method for this research is in user side using User Accepted Testing (UAT) as a standard and framework for testing in user side to completed testing in developer side [3]. The purpose of testing in user side using UAT is to reach the feedback from event organizer about how far system, data, and knowledge that gained, can help all of event organizer to manage tourism event data management and got the knowledge, that useful for strategy determination and decision making, in case of tourism event service for all tourists.

\section{DESIGN AND IMPLEMENTATION}

The Design of Gianyar Smart Tourism using Unified Modelling Language (UML) that consist of Use Case, Sequence Diagram, and Class Diagram. The implementation (coding) using PHP and MySQL in Linux, running on Apache Web Server. Cloud implementation using Openstack in Hybrid Cloud deployment. In this case, Hybrid Cloud combine both of internet and intranet around Gianyar Regency.

The picture below show the architecture of Gianyar Smart Tourism in Cloud network, including all user from event organizers and Gianyar Government office staffs.

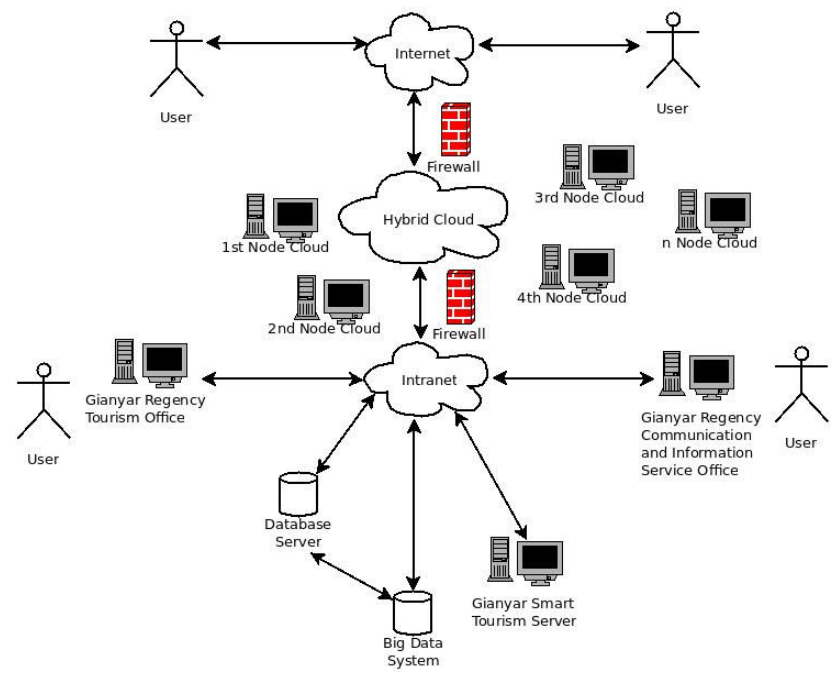

Fig. 1. Gianyar Smart Tourism architecture

The picture below shown Sequence Diagram as one of Unified Modelling Language (UML), for the case of tourism event data input by the user (administor and event organizer).

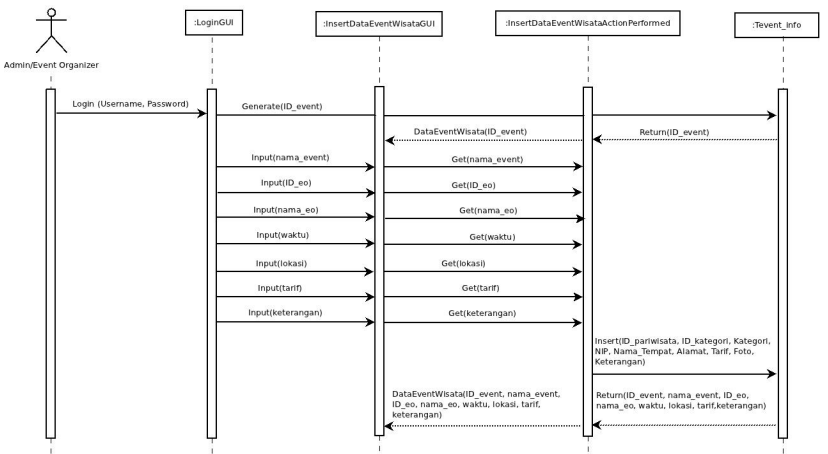

Fig. 2. Sequence Diagram for tourism event data input

The picture below shown the web based application on local server (Cloud Network) for Gianyar Smart Tourism, where all event organizers have their access into the system to manage the tourist event data. User of the system divided into 2 classes : administrator and event organizer.

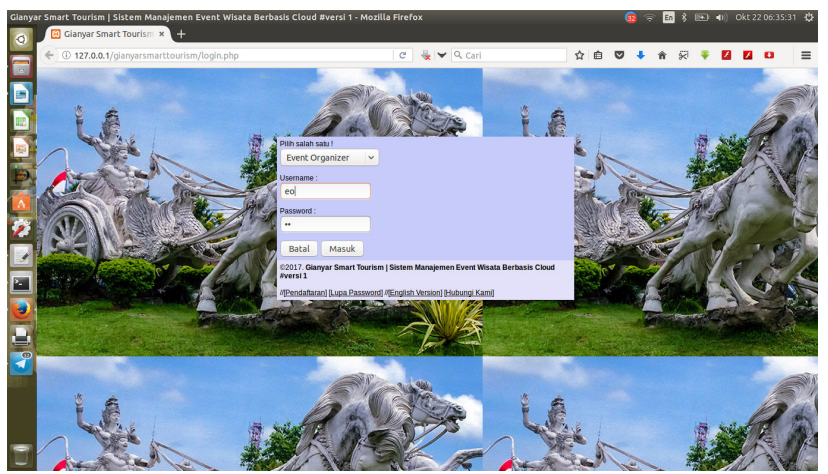

Fig. 3. Web based application for Gianyar Smart Tourism (local)

Testing from the local system (127.0.0.1), the picture below shown the implementation of database according to the ERD and also how it saved the tourism event data well. User (event organizer) input their tourism event data from web based user interface.

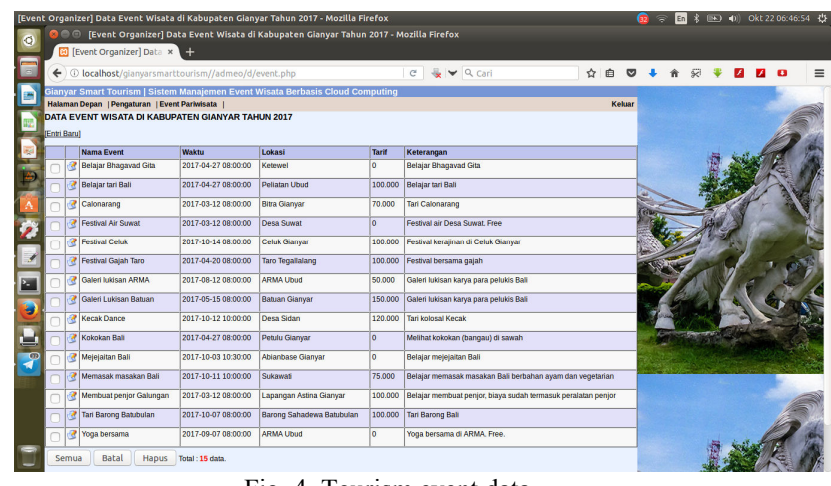

Fig. 4. Tourism event data

Tourism event data can be manage according to their event organizer, analyze, and show it to the tourist as a report and information, to make tourism service in Gianyar Regency better. 


\section{TESTING}

User Accepted Testing (UAT) in this research consist of three steps for the user (event organizer), including: 1)Testing of user experience, 2)Testing the input of data, 3)Testing for analyze and reporting from the system. The result show that most of user $(90 \%$ from 100 respondents) can be using Gianyar Smart Tourism (web based) easier to manage the tourism event data, both of personal computer and smartphone.The result also show that system can be process the data and report well.

\section{CONCLUSION}

The testing result showing that Tourism Event Management using Gianyar Smart Tourism based on Cloud, can help all event organizers to manage all tourism event data around Gianyar Regency easily. They also get the knowledge about tourist and tourism event object from the data, so that it can be used for decision making and strategy determination about tourism service in Gianyar Regency. It can be act as Knowledge Management too. The Cloud based make system and service better and more reliable.

\section{Acknowledgment}

This research supported by Udayana University (especially PNBP Using HUPS 2017 research funding), Gianyar Regency Tourism Office, Gianyar Government, event organizers and citizen around Gianyar Regency.

\section{References}

[1]Assi, M. "Knowledge Management in the Tourism and Leisure Industry With the Case Study of the Austrian National Tourist Office within the European Market”. Gent Belgium: University Gent. 2007.

[2]Frost, A. "A Synthesis of Knowledge Management Failure Factors". New York. Knowledge Management Tool. 2014.

[3]Goel, R. 2014. Survey on Acceptance Testing Technique. International Journal of Software and Web Sciences,8(1), March-May, 2014, pp. $20-23$

[4]Musulin, J. 2011. Knowledge Management in Tourism: the Importance of Tacit Knowledge and the Problem of its Elicitation and Sharing. Croatia. MIPRO 2011.

[5]Peffers, K., Tuunanen, T. Rothenberge, M.A., Chatterjee, S. A. "Design Science Research Methodology for Information Systems Research". Journal of Management Information Systems, Issue 3, Winter 20078, pp. 45-78. 2007.

[6]Simkova, E. "Knowledge Management in Tourism. Austria. ICL Conference". 2009. 